\title{
Efektivitas media berbasis augmented reality terhadap kemampuan anak tunarungu mengenal kebudayaan Yogyakarta
}

\author{
Yuli Imawati, Atien Nur Chamidah \\ Pendidikan Luar Biasa, Universitas Negeri Yogyakarta, Jalan Colombo No.1 Yogyakarta, 55281, \\ Indonesia \\ *Corresponding Author. E-mail: yuly233fip@student.uny.ac.id
}

\begin{abstract}
Abstrak: Penelitian ini bertujuan untuk mengetahui efektivitas media pembelajaran yang dikembangkan berbasis augmented reality terhadap hasil belajar mengenal kebudayaan dalam mata pelajaran IPS siswa tunarungu kelas V SLB B Karnnamanohara. Pendekatan penelitian yang digunakan yaitu kuantitatif dengan jenis penelitian kuasi eksperimen. Desain yang digunakan adalah bentuk one group pretes posttest design. Subjek dalam penelitian ini adalah siswa tunarungu kelas V SLB B Karnnamanohara yang berjumlah lima siswa. Teknik pengumpulan data yang digunakan adalah tes. Analisis data yang digunakan adalah statistik nonparametrik dengan mengunakan analisis Wilcoxon Test. Hasil penelitian menunjukan bahwa penggunaan media Yogya Monopoli efektif terhadap hasil belajar mengenal kebudayaan dalam mata pelajaran IPS siswa tunarungu kelas V SLB B Karnnamanohara. Hasil analisis data menggunakan Wilcoxon Test menunjukkan hasil perhitungan T hitung lebih kecil dari pada $\mathrm{T}$ tabel yaitu $0(\mathrm{p} \leq 0,05)$, sehingga Ho ditolak. Data hasil penelitian ini juga didukung dengan data hasil pencapaian posttest lebih baik dari hasil pencapaian pretest.
\end{abstract}

Kata kunci : anak tunarungu, hasil belajar, mengenal kebudayaan.

\section{The effectiveness of yogya monopoli media based on augmented reality toward deaf student ability to know the Yogyakarta culture}

\begin{abstract}
This study aim to determine the effectiveness of Yogya Monopoly media toward the learning outcome of culture in the social science subject for children with hearing impairment in grade 5th SLB Karnnamanohara. The research approach used is quantitative with quasi-experimental research type. The design used is one group pretest posttest design. Subjects used in this research are students with hearing impairment of class V in SLB Karnnamanohara. Data collection technique in this study is test. The data analysis used is nonparametric statistic by using Wilcoxon Test analysis. The results of the research showed that the use of Yogya Monopoly media was effective toward the learning outcomes of the culture in the subjects of social studies students with hearing impairment of class V in SLB Karnnamanohara. The result of data analysis which used Wilcoxon Test showed the result of calculation of $T$ count smaller than at $T$ table that was $0(p \leq 0,05)$, therefore Ho was rejected. The data of the study was supported by with data of posttest achievement which had higher result than the result of pretest achievement.
\end{abstract}

Keywords: hearing impairment, learning outcomes, culture.

\section{PENDAHULUAN}

Tunarungu adalah seseorang yang mengalami kekurangan atau kehilangan kemampuan mendengar baik sebagian atau seluruhnya yang diakibatkan oleh tidak berfungsinya sebagian atau seluruh alat pendengaran, sehingga anak tersebut tidak dapat menggunakan alat pendengarannya dalam kehidupan sehari-hari (Winarsih (2007:23). Hambatan tersebut mengakibatkan mereka memiliki perbendaharaan kosakata yang rendah, sulit memahami sesuatu yang bersifat abstrak dan terganggu bicaranya (Wasita, 2013:22). Selain itu, anak tunarungu memiliki permasalahan dalam penerimaan informasi dari lingkungan yang mengakibatkan prestasi belajar mereka lebih rendah daripada siswa normal terutama untuk pembelajaran yang bersifat abstrak dan hafalan seperti IPS. Salah satu materi dalam pembelajaran IPS yang bersifat abstrak dan hafalan adalah materi kebudayaan. 
Salah satu upaya yang dapat dilakukan untuk mengakomodasi dari hambatan yang dimiliki oleh anak tunarungu tersebut penggunaan media yang dapat mengoptimalkan indera yang lain terkhusus penglihatan sangat diperlukan sehingga permasalahan prestasi belajar yang rendah dapat teratasi. Esera (2008) dan Schick, Williams, dan Kupermintz (2006) menyoroti kebutuhan pendidikan anak tunarungu, bahwa kebutuhan pendidikan dari kelompok siswa ini adalah belajar dari lingkungan, komunikasi, menggunakan pendekatan visual, dan pembelajaran berbasis konkret.

Peranan indra penglihatan, selain sebagai sarana memperoleh pengalaman persepsi visual, juga sebagai ganti persepsi auditif anak tunarungu. Salah satu media yang sesuai dengan karakteristik dan kebutuhan anak tunarungu adalah media yang berbasis visual. Pemberian materi melalui media pembelajaran yang berbasis visual dapat merangsang anak tunarungu dalam menerima informasi.

Hal yang sama mengenai anak tunarungu yang merupakan pembelajar melalui indera visual disampaikan oleh Kuntze, Golos \& Enns (2014:214) yang menyebutkan bahwa "in deaf education the fact that deaf children are by nature visually oriented has been historically marginalized in favor of focusing on a lack of auditory access”. Sartika (2013:42), mengemukakan bahwa anak tunarungu memiliki keterbatasan dalam berbicara dan mendengar, sehingga media pembelajaran yang cocok untuk anak tunarungu adalah media visual.

Berdasarkan hasil observasi yang dilakukan di SLB Karnnamanohara dalam materi kebudayaan terdapat 3 dari 5 siswa yang mempunyai nilai dibawah rata-rata, selain itu salah satu kendala dalam pembelajaran adalah belum tersedia media yang mendukung pembelajaran materi kebudayaan. Media yang digunakan guru kelas dalam pembelajaran pengenalan kebudayaan adalah berupa gambar. Padahal penggunaan media pembelajaran merupakan salah satu strategi untuk membangkitkan motivasi dan rangsangan kegiatan belajar terhadap siswa (Arsyad, 2013:19-20). Media merupakan sarana pembelajaran yang digunakan untuk menyampaikan informasi kepada siswa yang bertujuan untuk membuat tahu siswa (Wiarto, 2016:3). Kurangnya media pembelajaran tersebut menyebabkan pembelajaran untuk anak tunarungu di SLB Karnnamanohara kurang interaktif dan anak sulit memahami materi yang dipelajari.

Salah satu cara untuk mengatasi masalah penggunaan media di atas adalah dengan menggunakan media Yogya Monopoli. Yogya Monopoli adalah media belajar yang dirancang untuk mengenalkan kebudayaan Yogyakarta pada siswa tunarungu. Media ini dirancang dalam bentuk permainan monopoli, suatu permainan yang dapat meningkatkan interaksi anak tunarungu dengan teman sebayanya. Media ini dilengkapi dengan Augmented Reality yang dapat membantu anak tunarungu memahami materi kebudayaan dengan cara memvisualisasikan suatu objek yang ada di kartu sehingga menyerupai bentuk asli. Permainan monopoli adalah permainan yang menggunakan satu set peralatan monopoli yang terdiri dari papan permainan, bidak atau petak, dua buah dadu, kartu dana umum, dan kesempatan, uang-uangan, kartu pembelian tanah, serta rumah-rumahan (Husna dalam Trinovitasari, 2015:13).

Augmented reality (AR) adalah kombinasi antara dunia maya (virtual) dan dunia nyata (real) yang dibuat oleh komputer (Suryawinata dalam Fernando (2013:1)). Objek virtual dapat berupa teks, animasi, model 3D atau video yang digabungkan dengan lingkungan sebernarnya sehingga pengguna merasakan objek virtual berada dilingkungannya. Materi yang tervisualisasikan dalam augmented reality adalah materi IPS yang berisi tentang kebudayaan. Materi tersebut tervisualisasikan dalam bentuk gambar, model 3D, teks, dan video, sehingga siswa dapat dengan mudah memahami materi yang disampaikan.

Penelitian ini bertujuan untuk mengetahui keefektifan media Yogya Monopoli terhadap hasil belajar mengenal kebudayaan dalam mata pelajaran IPS untuk siswa tunarungu kelas V SLB B Karnnamanohara. Hasil belajar adalah perubahan-perubahan yang terjadi pada diri siswa, baik yang menyangkut aspek kognitif, afektif, dan psikomotor sebagai hasil dari kegiatan belajar (Susanto (2013:5)). Evaluasi hasil belajar yang difokuskan pada penelitian ini adalah pada ranah kognitif. Berdasarkan ranah kognitif peneliti membatasi penelitian ini pada ranah C1 (mengingat) dan C2 (memahami). Hal ini karena disesuaikan dengan Kompetensi Dasar dalam mata pelajaran IPS yaitu siswa mampu mendeskripsikan keragaman suku bangsa di wilayahnya (provinsi/kabupaten/kota).

Adapun manfaat yang diharapkan dari hasil penelitian ini antara lain: (1) diharapkan dapat memberikan masukan dalam pembelajaran IPS, khususnya tentang penggunaan media Yogya Monopoli terhadap hasil belajar mengenal kebudayaan untuk siswa tunarungu kelas V, (2) Bagi guru diharapkan dapat digunakan sebagai alternatif media pembelajaran untuk mengajarkan materi 
pengenalan kebudayaan Yogyakarta dalam mata pelajaran IPS kelas V di SLB B Karnnamanohara, (3) Bagi siswa dapat membantu siswa tunarungu dalam memahami materi yang bersifat abstrak khususnya dalam materi pengenalan kebudayaan dan meningkatkan komunikasi serta pengembangan interaksi sosial, (4) Bagi sekolah dapat digunakan sebagai pertimbangan dalam membuat kebijakan pelaksanaan kurikulum dan peningkatan mutu pembelajaran dengan menggunakan media pembelajaran yang sesuai dengan karakteristik siswa tunarungu.

\section{METODE}

Jenis penelitian yang digunakan oleh peneliti adalah penelitian kuantitatif dengan metode penelitian kuasi eksperimen, yaitu desain yang digunakan karena pada kenyataannya sulit mendapatkan kelompok kontrol yang digunakan untuk penelitian (Sugiyono (2014: 77).

Penelitian dilaksanakan di SLB B Karnnamanohara yang berada di Jalan Pandean No.2, Depok, Condongcatur, Sleman, Kabupaten Sleman, Daerah Istimewa Yogyakarta. Penelitian dilaksanakan mulai bulan Juni-Juli 2017. Subjek dalam penelitian ini adalah siswa tunarungu SLB Karnnamanohara Yogyakarta Kelas V yang berjumlah 5 siswa. Desain penelitian yang digunakan dalam penelitian ini adalah model desain one-group pretest and posttest design. Dalam penelitian ini dilakukan sebanyak lima kali pertemuan, pertemuan I untuk melakukan pretest hasil belajar mengenal kebudayaan, pertemuan II, III, dan IV untuk melakukan tindakan/perlakuan, dan pertemuan V untuk melakukan posttest hasil belajar mengenal kebudayaan.

Prosedur perlakuan dalam pembelajaran yang diberikan yaitu:

\section{Pretest}

Pada pertemuan ini peneliti melakukan pretest hasil belajar mengenal kebudayaan. Peneliti memberikan soal pretest kepada siswa dengan waktu mengerjakan yaitu satu jam pelajaran atau 35 menit dengan 10 butir soal pilihan ganda.

2. Treatment

Pada pertemuan II, III, dan IV peneliti melakukan perlakuan/treatment. Peneliti berperan sebagai guru untuk memberikan treatment, sedangkan guru kelas berperan sebagai pembimbing dalam proses pembelajaran. Waktu pemberian treatment pada setiap pertemuan yaitu 70 menit atau dua jam pelajaran (@35 menit).

\section{Posttest}

Pada pertemuan ini peneliti melakukan posttest hasil belajar mengenal kebudayaan. Peneliti memberikan soal posttest kepada siswa dengan waktu mengerjakan yaitu satu jam pelajaran atau 35 menit dengan 10 butir soal pilihan ganda.

4. Tindak Lanjut

Pada tahap ini guru melakukan skoring dan penilaian hasil pretest dan posttest mengenal kebudayaan. Cara yang dilakukan untuk menghitung skor hasil belajar siswa menggunakan rumus skor tes pilihan ganda dengan sistem tanpa denda (Widoyoko, 2017:67).

Skor yang diperoleh siswa kemudian di ubah menjadi nilai dengan menggunakan rumus:

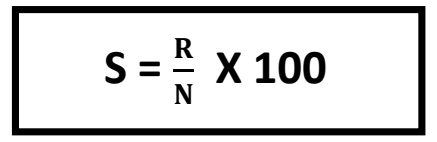

(Arikunto, 2013: 272) Keterangan:

S : Nilai pencapaian tes hasil belajar mengenal kebudayaan

$\mathrm{R}$ : Skor tes hasil belajar mengenal kebudayaan

$\mathrm{N}$ : Skor maksimum

Dalam penelitian ini teknik pengumpulan data yang digunakan adalah tes. Berdasarkan teknik pengumpulan data yang akan digunakan, maka alat pengumpul data dalam penelitian ini adalah tes hasil belajar. Metode tes yang digunakan pada penelitian ini bertujuan untuk mengetahui kemampuan awal subjek maupun kemampuan setelah diberikan perlakuan dalam hasil belajar mengenal 


\section{J PK (J urnal Pendidikan Khusus), 14 (1), 2018 - 29}

Yuli Imawati, Atien Nur Chamidah

kebudayaan melalui media Yogya Monopoli. Peneliti memberikan tes untuk menguji kemampuan siswa dalam menjodohkan nama benda sesuai gambar yang disediakan. Tes yang diberikan berjumlah 10 butir soal pilihan ganda.

Analisis data dalam penelitian ini dilakukan dengan menggunakan statistik nonparametrik yaitu dengan Wilcoxon Test, untuk melihat hasil belajar yang diperoleh oleh siswa sebelum (pretest) dan sesudah (posttest) dilakukan treatment.

\section{HASIL DAN PEMBAHASAN}

Hasil dari pelaksanaan penelitian ini untuk mengetahui perbedaan hasil belajar sebelum menggunakan media Yogya Monopoli. Pretest dilaksanakan pada tanggal 28 Juni 2017 pada pukul 08.00- 08.35 bertempat di ruang kelas V di SLB B Karnnamanohara. Berikut ini merupakan nilai pretest mengenal kebudayaan pada siswa tunarungu kelas V di SLB B Karnnamanohara dapat dilihat dalam tabel berikut :

Tabel 1. Data Hasil Nilai Pretest Mengenal Kebudayaan pada Siswa Tunarungu Kelas V di SLB B Karnnamanohara

\begin{tabular}{cccc}
\hline No. & Nama & Nilai pretest & Kriteria \\
\hline 1. & IN & 50 & K (Kurang) \\
2. & FB & 80 & B (Baik) \\
3. & FN & 50 & K (Kurang) \\
4. & AB & 50 & K (Kurang) \\
5. & RN & 10 & K (Kurang) \\
\hline
\end{tabular}

Berdasarkan data di atas dapat diketahui bahwa pada kemampuan awal siswa dalam materi kebudayaan diperoleh skor yang tertinggi dari 80 dan skor yang terendah adalah 10.

Posttest dilaksanakan pada tanggal 8 Juli 2017 pada pukul 08.00-08.35 bertempat di ruang kelas V di SLB B Karnnamanohara dengan lima subjek penelitian. Berikut ini merupakan nilai posttest mengenal kebudayaan pada siswa tunarungu kelas V di SLB B Karnnamanohara dapat dilihat dalam tabel berikut :

Tabel 2. Data Hasil Nilai Posttest Mengenal Kebudayaan pada Siswa Tunarungu Kelas V di SLB B

Karnnamanohara

\begin{tabular}{cccc}
\hline No. & Nama & Nilai Posttest & Kriteria \\
\hline 1. & IN & 80 & B (Baik) \\
2. & FB & 100 & SB (Sangat Baik) \\
3. & FN & 60 & C (Cukup) \\
4. & AB & 80 & B (Baik) \\
5. & RN & 30 & K (Kurang) \\
\hline
\end{tabular}

Berdasarkan data di atas dapat diketahui bahwa pada kemampuan akhir siswa dalam materi kebudayaan diperoleh skor yang tertinggi dari 100 dan skor yang terendah adalah 30.

Untuk mengetahui perbedaan skor pretest dan posttest pada kelima subjek mengenai mengenal kebudayaan dapat dilihat pada grafik histogram sebagai berikut:

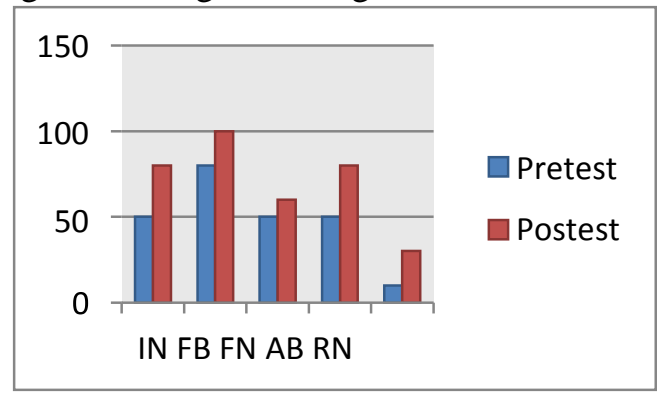

Gambar 1. Grafik Histogram Hasil Pretest dan Posttest Mengenal Kebudayaan 


\section{J PK (J urnal Pendidikan Khusus), 14 (1), 2018 - 30}

Yuli Imawati, Atien Nur Chamidah

Grafik di atas menunjukkan terjadi perbedaan nilai berupa peningkatan pengenalan kebudayaan berdasarkan nilai pretest dan posttest setelah diberikan perlakuan (treatment). Hal itu menunjukkan bahwa media Yogya Monopoli efektif terhadap peningkatan kemampuan pengenalan kebudayaan siswa tunarungu kelas V SLB B Karnnamanohara Yogyakarta.

Melalui data perbandingan nilai pretest dan posttest dapat dilihat bahwa pada saat sebelum diberikan treatment dengan media Yogya Monopoli (pretest) siswa FB memiliki nilai tertinggi yaitu 80, sedangkan setelah mendapatkan treatment dengan media Yogya Monopoli (posttest) siswa FB juga memiliki nilai tertinggi yaitu 100. Nilai siswa IN pada saat sebelum diberikan treatment dengan media Yogya Monopoli (pretest) yaitu 50, sedangkan sedangkan setelah mendapatkan treatment dengan media Yogya Monopoli (posttest) siswa IN yaitu 80. Nilai siswa FN sebelum diberikan treatment dengan media Yogya Monopoli (pretest) yaitu 50, sedangkan saat nilai setelah mendapatkan treatment dengan media Yogya Monopoli (posttest) siswa FN yaitu 60.

Analisis data dalam penelitian ini dilakukan dengan menggunakan statistik nonparametrik yaitu dengan Wilcoxon Test, untuk melihat hasil belajar yang diperoleh oleh siswa sebelum (pretest) dan sesudah (posttest) dilakukan treatment. Berdasarkan perhitungan diperoleh hilai $\mathrm{T}$ hitung $=0$, dan diperoleh $\mathrm{T}$ tabel $=1$. Oleh karena nilai $\mathrm{T}$ hitung dari Wilcoxon Test lebih kecil dari pada $\mathrm{T}$ tabel yaitu $0<1$, maka $\mathrm{Th}<\mathrm{Tt}$ sehingga Ho ditolak dan $\mathrm{H}_{1}$ diterima. Hasil tersebut menunjukkan bahwa hipotesis "Penggunaan media Yogya Monopoli efektif terhadap hasil belajar mengenal kebudayaan Yogyakarta pada mata pelajaran IPS untuk siswa tunarungu kelas V di SLB B Karnnamanohara”.

\section{PEMBAHASAN}

Tunarungu adalah anak yang mengalami kerusakan pada indera pendengaran, sehingga tidak dapat menangkap dan menerima rangsangan suara melalui pendengaran (Suharmini, 2009:35). Hambatan yang dimiliki oleh anak tunarungu tersebut mengakibatkan mereka memiliki karakteristik seperti perbendaharaan kosakata yang rendah, sulit memahami sesuatu yang bersifat abstrak dan terganggu bicaranya (Wasita, 2013:22). Keterbatasan tersebut mengharuskan anak tunarungu memerlukan adanya pengembangan dalam penggunaan media pembelajaran salah satunya dalam materi pembelajaran yang bersifat abstrak dan hafalan seperti dalam mata pelajaran IPS.

Keterbatasan yang dialami siswa tunarungu di kelas V SLB B Karnnamanohara dalam memahami materi pengenalan kebudayaan yaitu penggunaan media yang kurang bervariatif sehingga siswa belum mampu mengenal secara konkret jenis-jenis kebudayaan daerah. Hal yang dapat dilakukan untuk dapat memenuhi kebutuhan belajar yang efektif untuk siswa tunarungu yaitu dengan media yang tepat sesuai dengan kebutuhannya.

Menurut Indriana (2011:16) media pembelajaran adalah semua bahan dan alat fisik yang mungkin digunakan untuk mengimplementasikan pengajaran dan memfasilitasi prestasi siswa terhadap sasaran atau tujuan pengajaran. Salah satu cara yang dilakukan yaitu dengan memodifikasi dan mengembangkan media yang berbasis visual. Hal ini sesuai dengan cara belajar siswa tunarungu, menurut Efendi (2006:74) yang menyatakan bahwa fungsi penglihatan bagi anak tunarungu selain sebagai sarana memperoleh pengalaman persepsi visual, sekaligus sebagsai ganti persepsi auditif.

Mengingat anak tunarungu mempunyai gaya belajar tipe visual maka untuk membelajarkan sesuatu memerlukan obyek nyata atau konkrit. Hal ini disebabkan anak tunarungu menggunakan indera penglihatannya untuk tujuan kognitif, linguistik, dan komunikasi atau dijuluki sebagai pemata atau visualisers (A. Van Uden dalam Azizah (2008:3). Kondisi ini sejalan dengan pendapat Edgar Dale (dalam Sanjaya, 2006:166) bahwa semakin langsung objek yang dipelajari, maka makin konkrit pengetahuan yang diperoleh, semakin tidak langsung pengetahuan itu diperoleh, maka semakin abstrak pengetahuan siswa. Ada beberapa cara dan teknik untuk mengkongkretkan materi yang abstrak tersebut menggunakan enactve, iconic, dan symbolic melalui percontohan dengan gerak tubuh, gambar, peta, lambang, bagan, grafik, keterangan lanjut, atau elaborasi dalam kata-kata yang dapat dipahami oleh anak (Daryanto, 2014:66).

Salah satu cara untuk mengenalkan kebudayaan pada siswa tunarungu yaitu melalui media Yogya Monopoli berbasis augmented reality. Yogya Monopoli merupakan sebuah pengembangan permainan monopoli konvensional yang berguna sebagai media pembelajaran untuk anak tunarungu (Imawati, dkk, 2017:1). Media Yogya Monopoli dirancang dalam bentuk permainan monopoli yang berisi materi kebudayaan Yogyakarta dan dilengkapi dengan Augmented Reality yang dapat membantu anak tunarungu memahami materi kebudayaan dengan cara memvisualisasikan suatu objek yang ada 


\section{J PK (J urnal Pendidikan Khusus), 14 (1), 2018 - 31}

Yuli Imawati, Atien Nur Chamidah

di kartu sehingga menyerupai bentuk asli.

Langkah pembelajaran menggunakan media Yogya Monopoli yaitu terdiri dari tahap persiapan, pelaksanaan dan tindak lanjut. Tahap persiapan merupakan tahap untuk mempersiapkan hal-hal yang dibutuhkan secara teknis. Tahap pelaksanaan merupakan tahapan proses pembelajaran, pada proses pembelajaran siswa diajak untuk melihat dan mengamati gambar kebudayaan, mengamati video, dan kemudian membaca keterangan gambar, kemudian guru menjelaskan materi yang belum bisa dipahami siswa (menggunakan bahasa verbal dibantu dengan bahasa isyarat). Tahap tindak lanjut merupakan tahap evaluasi hasil belajar siswa, guru memberikan soal latihan untuk dikerjakan.

Hasil belajar merupakan faktor utama yang diamati dalam penelitian ini. Menurut Purwanto (2016:5) "hasil belajar merupakan perwujudan kemampuan akibat perubahan perilaku yang dilakukan oleh usaha pendidikan”. Fokus hasil belajar yang diamati adalah mengenai pengenalan kebudayaan Yogyakarta dengan melakukan pretest dan posttest. Hasil belajar mengenal kebudayaan yang dimaksud dalam penelitian ini adalah perolehan kemampuan pemahaman siswa dari proses belajar siswa terhadap kompetensi mengenal kebudayaan, sehingga siswa dapat membedakan berbagai macam jenis kebudayaan Yogyakarta (tarian adat, pakaian adat, makanan khas, rumah adat, senjata adat, alat musik daerah).

Dalam penelitian ini pretest dan posttest dilaksanakan sebanyak 1 kali dengan butir soal yang sama. Pretest digunakan untuk mengukur hasil belajar siswa sebelum diberikan treatment, sedangkan posttest digunakan untuk mengetahui hasil belajar siswa setelah mendapatkan treatment.

Dalam mengetahui efektivitas penggunaan media Yogya Monopoli terhadap hasil belajar siswa tunarungu, maka dilakukan pengujian hipotesis. Pengujian hipotesis dalam penelitian ini menggunakan Wilcoxon Test. Berdasarkan analisis menggunakan Wilcoxon Test diperoleh nilai $\mathrm{T}$ hitung dari Wilcoxon Test lebih kecil dari pada T tabel $0<1$, maka maka Th $<$ Tt sehingga Ho ditolak. Hasil tersebut menunjukkan bahwa penggunaan media Yogya Monopoli efektif terhadap hasil belajar mengenal kebudayaan Yogyakarta pada mata pelajaran IPS untuk siswa tunarungu kelas V di SLB B Karnnamanohara.

Melalui data perbandingan nilai pretest dan posttest dapat dilihat bahwa pada saat sebelum diberikan treatment dengan media Yogya Monopoli (pretest) siswa FB memiliki nilai tertinggi yaitu 80, sedangkan setelah mendapatkan treatment dengan media Yogya Monopoli (posttest) siswa FB juga memiliki nilai tertinggi yaitu 100. Nilai siswa IN pada saat sebelum diberikan treatment dengan media Yogya Monopoli (pretest) yaitu 50, sedangkan sedangkan setelah mendapatkan treatment dengan media Yogya Monopoli (posttest) siswa IN yaitu 80.

Nilai siswa FN sebelum diberikan treatment dengan media Yogya Monopoli (pretest) yaitu 50, sedangkan saat nilai setelah mendapatkan treatment dengan media Yogya Monopoli (posttest) siswa FN yaitu 60. Nilai siswa AB sebelum diberikan treatment dengan media Yogya Monopoli (pretest) yaitu 50, sedangkan saat nilai setelah mendapatkan treatment dengan media Yogya Monopoli (posttest) siswa $\mathrm{AB}$ yaitu 80. Nilai siswa RN sebelum diberikan treatment dengan media Yogya Monopoli (pretest yaitu 10, sedangkan saat nilai setelah mendapatkan treatment dengan media Yogya Monopoli (posttest) siswa RN yaitu 30.

Melalui analisis nilai pretest dan posttest tersebut subjek IN mengalami peningkatan nilai 30\%, subjek FB mengalami peningkatan nilai $20 \%$, subjek FN mengalami peningkatan nilai $10 \%$, subjek AB mengalami peningkatan nilai 30\%, dan subjek RN mengalami peningkatan nilai $20 \%$.

Pada temuan penelitian didapatkan bahwa nilai semua siswa mengalami peningkatan, namun terdapat 2 dari 5 siswa yang nilainnya meningkat, akan tetapi nilainya masih dibawah KKM yaitu FN dan RN. Hal ini dikarenakan kedua siswa tersebut memiliki hambatan dalam aspek intelegensi yaitu kemampuan berpikir dibawah rata-rata, dan juga memiliki permasalahan dalam pengendalian emosi.

Berdasarkan data nilai pretest dan posttest tersebut maka dapat diketahui bahwa terdapat kenaikan nilai setelah penggunaan media Yogya Monopoli. Hal tersebut sesuai dengan pernyataan Arsyad (2013) bahwa penggunaan media pembelajaran pada tahap orientasi pembelajaran akan sangat membantu keefektifan proses pembelajaran serta penyampaian pesan dan isi pelajaran pada saat itu. Selain membangkitkan motivasi dan minat siswa, media pembelajaran juga dapat membantu siswa meningkatkan pemahaman, menyajikan data dengan menarik dan terpercaya, memudahkan penafsiran data, dan memadatkan informasi.

Berdasarkan manfaat media pembelajaran, maka media pembelajaran merupakan salah satu teknik yang sesuai untuk meningkatkan hasil belajar. Penggunaan media Yogya Monopoli dalam 


\section{J PK (J urnal Pendidikan Khusus), 14 (1), 2018 - 32}

Yuli Imawati, Atien Nur Chamidah

pembelajaran bagi siswa tunarungu merupakan salah satu cara yang bisa dilakukan oleh guru untuk mengenalkan kebudayaan secara semi konkret melalui visual. Memaksimalkan kemampuan visual adalah kompensatoris dari keterbatasan pendengaran. Darmawan (2012:15) mengemukakan bahwa dalam bentuknya yang paling murni, media visual dapat membawakan pesan yang lengkap.

Penggunaan media Yogya Monopoli yang berbasis visual juga sesuai dengan cara belajar anak tunarungu yang merupakan pembelajar melalui indera visual disampaikan oleh Kuntze, Golos and Enns (2014:214) yang menyebutkan bahwa "in deaf education the fact that deaf children are by nature visually oriented has been historically marginalized in favor of focusing on a lack of auditory access". Artinya siswa tunarungu belajar menggunakan kemampuan visualnya untuk memahami materi pelajaran.

Materi yang tervisualisasikan dalam augmented reality adalah materi IPS yang berisi tentang kebudayaan. Materi tersebut tervisualisasikan dalam bentuk gambar, model 3D, teks, dan video, sehingga siswa dapat dengan mudah memahami materi yang disampaikan. Hal tersebut sesuai dengan tujuan dari pengembangan augmented reality adalah menambahkan pengertian dan informasi dunia nyata dimana sistem augmented reality mengambil dunia nyata sebagai dasar dan menggabungkan beberapa teknologi dengan menambahkan data kontekstual agar pemahaman seseorang menjadi semakin jelas (Husni, \& Rokhmat, dkk, 2008:2).

Kemampuan visual augmented reality berguna dalam banyak aplikasi seperti dalam mengajarkan konsep abstrak dalam belajar ilmu pengetahuan (Zainuddin, Zaman, \& Ahmad, 2010). Ada beberapa studi dalam literatur ilmiah yang menghubungkan teknologi virtual dengan peningkatan kinerja akademis dan motivasi siswa (Di Serio, Ibáñez, \& Kloos, 2013; Holley, Hobbs, \& Menown, 2016), keterampilan sosial dan kolaboratif siswa dan keterampilan psikomotor dan kognitif siswa (Feng, Duh, \& Billinghurst, 2008).

Augmented reality juga dapat mempertahankan keterlibatan siswa, karena menarik dan menantang untuk berinteraksi, menciptakan, dan memanipulasi objek di lingkungan virtual. Kelebihan dari animasi yang terdapat pada media pembelajaran augmented reality menjadikan objek terlihat lebih jelas dan real, sehingga siswa seolah melihat objek tersebut secara nyata ada di hapadannya. Animasi yang ditampilkan dalam media pembelajaran augmented reality dapat dilihat dengan waktu yang lebih lama dan secara berulang.

Melalui media Yogya Monopoli yang berbasis augmented reality siswa mendapatkan pengalaman langsung terkait materi kebudayaan tanpa harus berkunjung ke daerah tersebut. Media ini dapat dikatakan efisien karena dengan media pembelajaran berbasis augmented reality kita tidak perlu membawa alat peraga ke dalam kelas, namun materi yang dipelajari tetap dapat ditampilkan di dalam kelas.

Media Yogya Monopoli merupakan media pembelajaran dengan sistem permainan. Penggunaan media pembelajaran dengan sistem permainan digunakan karena akan lebih bermakna ketika siswa mengalami apa yang sedang dipelajari. Hal tersebut sependapat dengan Siskawati, Pargito, \& Pujiati (2016:74) melalui pembelajaran dengan sistem permainan diharapkan dapat menimbulkan kegiatan belajar mengajar yang menarik dan langsung melibatkan siswa secara aktif sehingga dapat membuat pembelajaran tidak membosankan, melatih kerjasama, meningkatkan pemahaman siswa terhadap materi yang diajarkan, menumbuhkan minat belajar, mempercepat proses informasi serta menyelesaikan masalah sekaligus meningkatkan kepekaan sosial.

Penerapan media Yogya Monopoli dalam pembelajaran pengenalan kebudayaan untuk anak tunarungu juga sesuai dengan tujuan pendekatan konstruktivis. Pendekatan konstruktivistik adalah pembelajaran yang menekankan pada peran aktif siswa dalam membangun pemahaman dan memberi makna terhadap informasi atau peristiwa yang dialami (Woolfolk (2003)). Adapun dalampembelajaran konstruktivisme, yang menjadi pusat perhatian adalah siswa. Peran guru adalah sebagai fasilitator, terapis bahkan sebagai liberator (pembebas) (A Lefrancois and Guy R; 2000: 203204)). Menurut Karfi, dkk (2002:6) tujuan dilaksanakannya pembelajaran konstruktivisme yaitu memberikan kesempatan kepada siswa untuk berinteraksi langsung kepada benda- benda konkrit ataupun model artifisial, hal tersebut juga sesuai dengan (Winn, 2002) yang menyatakan bahawa pendekatan konstruktivisme ini mampu mempromosikan pengalaman belajar yang berpusat pada siswa, mengingat bahwa siswa adalah pemain utama saat bereksperimen dan berlatih dengan benda virtual. 


\section{JPK (J urnal Pendidikan Khusus), 14 (1), 2018 - 33}

Yuli Imawati, Atien Nur Chamidah

\section{SIMPULAN}

\section{Simpulan}

Berdasarkan hasil penelitian yang telah diperoleh mengenai penerapan media Yogya Monopoli, maka dapat ditarik kesimpulan bahwa terdapat kenaikan nilai setelah penggunaan media Yogya Monopoli pada materi mengenal kebudayaan dalam mata pelajaran IPS siswa tunarungu kelas V SLB B Karnnamanohara, hal ini dapat dilihat dari hasil uji tes dari penggunaan media Yogya Monopoli.

Dari hasil penelitian uji sigifikansi ditemukan $\mathrm{T}$ hitung lebih kecil dari pada $\mathrm{T}$ tabel yaitu $0<1$, maka $\mathrm{Th}<\mathrm{Tt}$ sehingga Ho ditolak dan $\mathrm{H}_{1}$ diterima. Berdasarkan hal tersebut dapat disimpulkan bahwa media Yogya Monopoli efektif terhadap hasil belajar mengenal kebudayaan Yogyakarta pada mata pelajaran IPS untuk siswa tunarungu kelas V di SLB B Karnnamanohara.

\section{Saran}

Berdasarkan hasil penelitian yang telah dilakukan, peneliti memberikan beberapa saran, yakni:

1. Bagi Guru

Guru hendaknya menerapkan media Yogya Monopoli sebagai salah satu media untuk mengenalkan Kebudayaan Yogyakarta pada siswa tunarungu.

2. Bagi Peneliti Selanjutnya

Perlu dilakukan pengembangan pada konten dan fitur yang terdapat dalam media Yogya Monopoli, sehingga media lebih menarik dan konten yang didalamnya lebih bervariatif.

\section{DAFTAR PUSTAKA}

A Lefrancois and Guy R. (2000). Psychology for Teaching. USA: (Wadsworth Thomson Learing).

Arsyad, A. (2013). Media Pembelajaran. Jakarta : Raja Grafindo Persada.

Azizah, N. (2008). Model Pembelajaran Kooperatif Tipe Think Pair Share Untuk Aktivitas Siswa Dan Hasil Belajar Matematika Anak Tunarungu. Jurnal Pendidikan Luar Biasa, April 2008, Volume 4, Nomor 1.

Darmawan, D. (2012). Inovasi Pendidikan Pendekatan Praktik Teknoogi Multimedia dan Pembelajaran Online. Bandung: PT Remaja Rosdakarya.

Daryanto. (2014). Pembelajarn Tematik, Terpadu, Terintegrasi (Kurikulum 2013). Yogyakarta : Gava Media.

Efendi, M. (2006). Pengantar Psikopedagogik Anak Berkelainan. FKIP UNS : Surakarta.

Esera, T. (2008). An Insight Into The Educational Needs Of Deaf High School Students: Interviews With School Staff And Students.The Journal of Kairaranga, 9(2), 32-36.

Feng, Z, Duh, H.B.L, \& Billinghurst, M. (2008). Trends in augmented reality tracking, interaction and display: A review of ten years of ISMAR. Cambridge, UK. doi: 10.1109/ISMAR.2008.4637362.

Fernando, M. (2013). Membuat Aplikasi Android Augmented Reality Menggunakan Vuforia SDK dan Unity. Solo: Buku AR Online.

Holley, D., Hobbs, M., \& Menown, C. (2016). The Augmented Library: Motivating STEM Students. Networks, 19, 77-84.

Husni, E.M, \& Rokhmat. Y, dkk. (2008). Perancangan Augmented Reality Volcano untuk Alat Peraga Museum. Jurnal Institut Teknologi Bandung. 


\section{J PK (J urnal Pendidikan Khusus), 14 (1), 2018 - 34}

Yuli Imawati, Atien Nur Chamidah

Imawati, Y, dkk. (2017). Pengembangan "Yogya Monopoli": Media Pembelajaran Kebudayaan Berbasis Augmented Reality Untuk Anak Tunarungu. Laporan Penelitian yang Dimasukan dalam Pekan Ilmiah Nasional Mahasiswa 30 di Universitas Muslim Indonesia.

Indriana, D. (2011). Ragam Alat Bantu Media Pembelajaran. Yogyakarta : Diva Press Jogjakarta.

Kuntze, Marlon, D. Golos, C, \& Enns. (2014). Rethinking Literacy: Broadening Opportunities for Visual Learners. Sign Language Studies. Volume 14, Number 2, Winter 2014, pp 203-224.

Purwanto. (2016). Evaluasi Hasil Belajar. Yogyakarta : Pustaka Pelajar.

Sanjaya, W. (2006). Strategi Pembelajaran. Jakarta: Kencana.

Sartika, Y. (2013). Ragam Media Pembelajaran Adaptif untuk Anak Berkebutuhan Khusus. Yogyakarta : Familia.

Schick, B., Williams, K., \& Kupermintz H. (2006). Look who's being behind: Educational interpreters and access to education for deaf and hard-of- hearing students. Journal deaf studies and deaf education, 11(1), 3-20. 3-20.

Siskawati, M, Pargito, \& Pujiati. (2016). Pengembangan Media Pembelajaran Monopoli Untuk Meningkatkan Minat Belajar Geografi Siswa. Jurnal Studi Sosial Vol 4, No 1 (2016), 72-80.

Sugiyono. (2013). Metode Penelitian Pendidikan: Pendekatan Kuantitatif, Kualitatif, dan R\&D. Bandung: Alfabeta.

Susanto, A. (2013). Teori Belajar dan Pembelajaran di Sekolah Dasar. Jakarta : Prenadamedia Group.

Wasita, A. (2013). Seluk Beluk Tunarungu dan Tunawicara Serta Strategi Pembelajarannya. Yogyakarta: Javalitera.

Wiarto, G. (2016). Media Pembelajaran dalam Pendidikan Jasmani. Yogyakarta : Laksita.

Widoyoko, E. P. (2017). Evaluasi Progra Pembelajaran : Panduan Praktis Bagi Pendidik Dan Calon Pendidik. Yogyakarta : Pustaka Pelajar.

Winarsih, M. (2007). Intervensi Dini Bagi Anak Tunarungu Dalam Pemerolehan Bahasa. Departemen Pendidikan dan Kebudayaan. Direktorat Jenderal Pendidikan Tinggi.

Winn, W. (2002). "Research into practice: Current trends in educational technology research: The study of learning environments”. Educational Psychology Review, 14(3), 331-351.

Woolfolk, A. (2004). Educational Psychology. New York: Pearson.

Zainuddin, N. M. M, Zaman, H. B, \& Ahmad, A. (2010). Developing Augmented Reality book for deaf in science: The determining factors. International Symposium on Information Technology, Kuala Lumpur, pp. 1-4. 